\title{
Simulation analysis of regional real estate investment risk based on System dynamics
}

\author{
Ying Wang ${ }^{1 *}$, Mingwei Zhang ${ }^{2}$ \\ ${ }^{1}$ Department of Management, Renai College of Tianjin University, Tianjin, 301636, China \\ ${ }^{2}$ Department of Management, Renai College of Tianjin University, Tianjin, 301636, China
}

\begin{abstract}
The high risk of real estate investment is the main obstacle to the orderly and healthy development of regional real estate market. To study the risk of real estate investment, it is necessary to analyze its influencing factors. This paper takes Tianjin as an example, based on six subsystems such as market factors and economic factors, analyzes the influencing factors of each subsystem, and synthetically determines the weight Coefficient of the index, constructing the risk System dynamics model of real estate investment. The result shows that the rise of interest rate and public emergency will bring great risk to the development of Tianjin real estate market. Finally, from the government's point of view to establish a risk control mechanism for real estate enterprises to reduce the risk of investment to make reasonable recommendations.
\end{abstract}

\section{Introduction}

Since the 1990s, China's real estate industry has gradually entered the era of vigorous development, the real estate market in many cities has developed rapidly, it is obvious that the real estate industry has become a pillar industry supporting local economic development. However, in the past two years, the international and domestic economic situation has begun to show "uncertainty", the real economy has gradually appeared a downward trend. While the country's "two-child policy" and Tianjin's "Hai River Talent Action Plan", launched in the first half of 2018, appear to have brought real estate developers unlimited business opportunities. However, the implementation of the "five limits" policy accelerated the adjustment and reshuffle of real estate, which hindered the financing of the domestic market, aggravated the risks and intensified the competition. At the same time, as a result of the large-scale outbreak of COVID-19 in early 2020, construction sites have been stopped and sold all over the country, which has had a great impact on the real estate industry. With the passage of time, its negative impact has gradually emerged, for the Real Estate Enterprise Future Sustainable Development has brought the bigger risk. Therefore, the study of Real Estate Market Investment Risk, analysis of its influencing factors, to promote the healthy and stable development of China's real estate industry is of great significance.

At present, some domestic and foreign scholars on real estate investment will encounter the risk of analysis and prediction. From the qualitative point of view, Zhao Ling ${ }^{[1]}$ identified the risk factors in the whole process of real estate investment projects, and put forward the risk prevention strategy. Xiaoying Deng ${ }^{[2]}$ and others analyze the impact of risk on investment decision-making of Real Estate Enterprises through empirical research. Liu Wei proposed that the construction of real estate projects in the process of the economic situation, project location and other aspects of key control, so as to reduce the risk ${ }^{[3]}$. In terms of the Quantitative analysis method, Huang Mengfei et Al. analyzed the interaction and correlation mechanism of risk control decision among real estate enterprises by using Bayesian network simulation ${ }^{[4]}$. When using analytic hierarchy process (AHP), combined with mould and theory, Zhou Qiqing established a multilevel index system of risk factors, which provided a reasonable method for scientific and reasonable evaluation $^{[5]}$. Zhang Ping et $\mathrm{AL}$ constructed the risk evaluation model of real estate industry by using grey model and mathematical theory, and proved the feasibility and applicability of the model by demonstration ${ }^{[6]}$.

To sum up, scholars at home and abroad have conducted in-depth studies on the possible risks in the real estate market, but in different periods, in different places, the uncertain factors are constantly changing, and the relationship between the risk factors is becoming more and more complex, the real estate enterprise must face the investment risk difficult question still exists. Therefore, on the basis of previous studies, this paper identifies the risk factors that real estate enterprises may encounter when they invest, and analyzes the cause and effect relationship among the factors, and quantifies them by introducing the method of System dynamics, using Vensim software to carry out simulation, find out the current and future period of real estate enterprise threat the biggest risk, and put forward relevant suggestions and measures of risk aversion. 


\section{Introduction to System dynamics}

System Dynamics is a science that combines the theory of systems science with computer simulation to study the feedback structure and behavior of systems ${ }^{[7]}$. Based on the theories of Cybernetics, system theory, decision theory and so on, from the dynamic point of view, it constructs the system model, shows and controls the law of system change and development, and then gives back to the system and optimizes and controls $\mathrm{it}^{[8]}$. The process of investment risk analysis in real estate market based on System dynamics theory mainly includes: (1) selecting variables according to the system behavior; (2) designing the causality diagram of the system, defining the parameters, and determining the system equation, (3) after determining the system boundary, the variables and the function relations, according to the time investigation and the data analysis, using the Vensim software to carry on the simulation, analyzes and observes the dynamic evolution result of the model, the development trend of the real estate market risk in Tianjin is forecasted and analyzed $^{[9]}$.

\section{Influence factors and causality of regional real estate investment risk}

\subsection{Influencing factors of investment risk in regional real estate market}

Real estate investment plays a very important role in promoting the growth of China's economy, but it has the characteristics of huge investment, long lasting cycle, complex and changeable environment, etc, if you want to reduce the risk of investment must consider a number of uncertainties. In order to be able to objectively and reasonably analyze the impact of various factors on real estate development enterprises, on the basis of market research and literature summary, combining the relevant data on real estate investment in the past 10 years from databases such as "China economic and social big data research platform", "China real estate big data information platform" and "Tianjin Economic and Social Development Statistics Database" , a summary Table of the factors influencing the investment risk of Tianjin real estate market is constructed, which is shown in Table 1.

Table 1. Influencing factors of investment risk in real estate market

\begin{tabular}{|c|c|}
\hline Risk Factor & Content description \\
\hline \multirow{2}{*}{ Market risk( $\left.\mathrm{a}_{1}\right)$} & $\begin{array}{l}\text { Change in supply and } \\
\text { demand(a }\left(\mathrm{a}_{11}\right)\end{array}$ \\
\hline & $\begin{array}{l}\text { Change in demand } \\
\text { structure }\left(\mathrm{a}_{12}\right)\end{array}$ \\
\hline \multirow{2}{*}{ Policy risk(a $\left.\mathrm{a}_{2}\right)$} & Policy Adjustment(a 21$)$ \\
\hline & A broken law( $\left.\mathrm{a}_{22}\right)$ \\
\hline \multirow{3}{*}{ Economic risk $\left(\mathrm{a}_{3}\right)$} & Inflation( $\left.\mathrm{a}_{31}\right)$ \\
\hline & Financing difficulties( $\left.\mathrm{a}_{32}\right)$ \\
\hline & Change in interest rates(a33) \\
\hline \multirow{2}{*}{ Technical risk(a4) } & Technology Promotion(a41) \\
\hline & Technical applicability(a42) \\
\hline \multirow[t]{2}{*}{ Information $\operatorname{risk}\left(\mathrm{a}_{5}\right)$} & $\begin{array}{l}\text { Information } \\
\text { Asymmetry(a51) }\end{array}$ \\
\hline & Information $\operatorname{Lag}\left(\mathrm{a}_{52}\right)$ \\
\hline \multirow[b]{2}{*}{ Environmental risk(a6) } & Public Emergency(a61) \\
\hline & $\begin{array}{l}\text { Meteorological, Flood and } \\
\text { drought and other natural } \\
\text { disasters }\left(\mathrm{a}_{62}\right)\end{array}$ \\
\hline
\end{tabular}

\subsection{Cause and effect circuit diagram of investment risk in regional real estate market}

The basis of constructing the System dynamics model is to analyze the relationship among the factors influencing the investment risk in the regional real estate market, and to draw the circulation chart of the primary cause and effect relationship with the feedback principle of the System dynamics ${ }^{[10]}$. Therefore, after determining the key factors of investment risk encountered in Tianjin real estate market in recent years, according to its logical relationship with the border risk factors, the risk factors are fitted into a systematic whole, and the risk causality circuit diagram is established, as shown in Figure 1. The "+" arrow in the figure indicates that the change of a factor will cause the increase of related variables, while the" "arrow indicates that the change of a factor will cause the decrease of related variables ${ }^{[10]}$. 


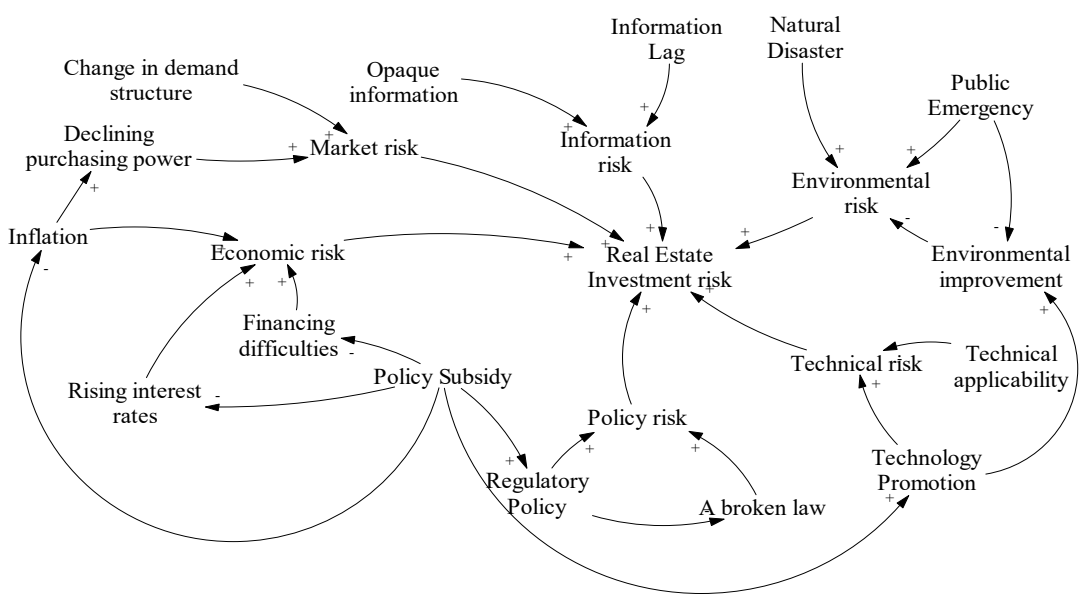

Figure 1. Tianjin Real Estate Investment Risk System Causal Circuit Diagram

It can be seen from the graph that in the course of real estate project investment, the economic risks such as interest rate rise, inflation, market supply and demand change are likely to occur. At the same time, the imperfect laws and regulations, policy changes and so on will cause the risk probability of policy greatly increased. In addition, unexpected public events, such as the outbreak of COVID-19 in 2020, meteorological and flood disasters in the south, and environmental protection measures in the Beijing-Tianjin-Hebei region in winter will directly or indirectly affect the investment environment, cause or reduce environmental risk.

\section{Regional Real Estate Investment Risk System Dynamics}

\subsection{Regional Real Estate Investment Risk System Dynamics}

The causal feedback loop diagram of the system can be used to understand the mutual influence and restriction of various factors at the initial stage of modeling, but when the real estate investment system needs to be quantified and simulated, it is far from enough to establish causality diagram, then, we need to study the real estate investment risk factors on the basis of causal loop diagram, according to the relationship between the flow and stock principle, the construction of System dynamics, see figure 2.

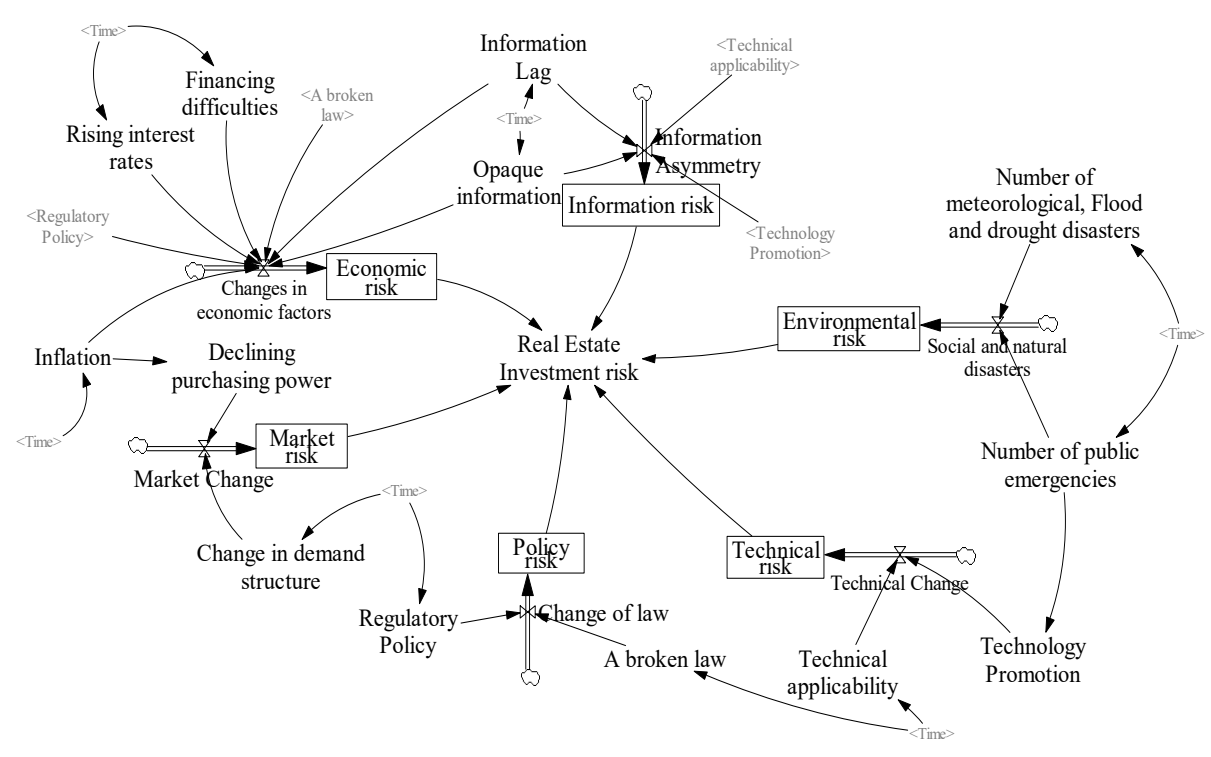

Figure 2. Tianjin real estate investment risk system flow chart 
As can be seen from the graph above, the risk of real estate investment is taken as the output of the system, which is affected by economic risk, technical risk, market risk and environmental risk. When constructing the system flow diagram, the six subsystems are modeled as stocks, and the other factors that can cause the stocks to change are modeled as auxiliary variables, exogenous variables or constants.

\subsection{Risk factor assignment based on entropy weight method}

The determination of the value of the boundary risk in the regional real estate investment risk system is a very important step after the construction of the system flow chart. Based on the border risks shown in the figure above, in which public emergencies, meteorological disasters and floods and droughts can be obtained through statistical data, and the remaining data on risk factors need to be obtained through questionnaire surveys, that is to say, the weight of risk factors is determined by means of the combination of expert scoring and entropy weight assignment, and the effect degree of each factor on risk is examined.

On the basis of the investment risk evaluation index system of Tianjin Real Estate Project, five experts and scholars from colleges and universities in the field of real estate, practitioners in the field of real estate and staff of financial institutions were invited, with reference to relevant literature, rank the risk on a five-point scale ${ }^{[11]}$. According to the criteria of greater influence [90,100], general influence [80,90], lesser influence [70,80] and little influence $[60,70]$, the indexes are scored, and the corresponding scoring data are obtained, as shown in Table 2.

Table 2. Tianjin Real Estate Investment Risk Index rating table

\begin{tabular}{c|c|c|c|c|c|c|c|c|c|c|c|c|c}
\hline Indicators & $\mathrm{a}_{11}$ & $\mathrm{a}_{12}$ & $\mathrm{a}_{21}$ & $\mathrm{a}_{22}$ & $\mathrm{a}_{31}$ & $\mathrm{a}_{32}$ & $\mathrm{a}_{33}$ & $\mathrm{a}_{41}$ & $\mathrm{a}_{42}$ & $\mathrm{a}_{51}$ & $\mathrm{a}_{52}$ & $\mathrm{a}_{61}$ & $\mathrm{a}_{62}$ \\
\hline 1 & 90 & 80 & 90 & 75 & 85 & 90 & 80 & 85 & 90 & 95 & 90 & 90 & 65 \\
\hline 2 & 85 & 75 & 70 & 60 & 70 & 75 & 75 & 75 & 90 & 80 & 95 & 90 & 70 \\
\hline 3 & 80 & 85 & 80 & 60 & 90 & 95 & 80 & 75 & 85 & 90 & 85 & 85 & 65 \\
\hline 4 & 80 & 80 & 85 & 75 & 80 & 85 & 80 & 75 & 80 & 85 & 90 & 95 & 70 \\
\hline 5 & 80 & 70 & 85 & 70 & 85 & 80 & 70 & 80 & 85 & 80 & 80 & 85 & 70 \\
\hline
\end{tabular}

\subsubsection{Analysis of data reliability test}

In order to test the reliability of the data obtained by the expert scoring method, this paper selects the most widely used reliability testing method, which is suitable for the attitude and opinion questionnaire ${ }^{[12]}$. According to the method, if the Cronbach's alpha is greater than 0.700 , the result is credible. The reliability Coefficient is 0.742 when the above data are inputted into the SPSS software.

$$
a=\left[\begin{array}{lllllllllllll}
90 & 80 & 90 & 75 & 85 & 90 & 80 & 85 & 90 & 95 & 90 & 90 & 65 \\
85 & 75 & 70 & 60 & 70 & 75 & 75 & 75 & 90 & 80 & 95 & 90 & 70 \\
80 & 85 & 80 & 60 & 90 & 95 & 80 & 75 & 85 & 90 & 85 & 85 & 65 \\
80 & 80 & 85 & 75 & 80 & 85 & 80 & 75 & 80 & 85 & 90 & 95 & 70 \\
80 & 70 & 85 & 70 & 85 & 80 & 70 & 80 & 85 & 80 & 80 & 85 & 70
\end{array}\right]
$$

(2) standardized conversion of raw data to a standardized Matrix:

$$
c=\left[\begin{array}{lllllllllllll}
0.00 & 0.33 & 0.00 & 0.00 & 0.25 & 0.25 & 0.00 & 0.00 & 0.00 & 0.00 & 0.33 & 0.50 & 1.00 \\
0.50 & 0.67 & 1.00 & 1.00 & 1.00 & 1.00 & 0.50 & 1.00 & 0.00 & 1.00 & 0.00 & 0.50 & 0.00 \\
1.00 & 0.00 & 0.50 & 1.00 & 0.00 & 0.00 & 0.00 & 1.00 & 0.50 & 0.33 & 0.67 & 1.00 & 1.00 \\
1.00 & 0.33 & 0.75 & 0.00 & 0.50 & 0.50 & 0.00 & 1.00 & 1.00 & 0.67 & 0.33 & 0.00 & 0.00 \\
1.00 & 1.00 & 0.75 & 0.33 & 0.25 & 0.75 & 1.00 & 0.00 & 0.50 & 1.00 & 1.00 & 1.00 & 0.00
\end{array}\right]
$$

(3) according to the formula of entropy value, the entropy weight and weight of each index are determined:
Therefore, the design and scoring data of the questionnaire are reasonable and the reliability is credible.

\subsubsection{Determine the weight of the index}

After the initial value of the risk evaluation index is determined by the expert scoring method, the final weight value of each kind of boundary risk is calculated by the entropy weight method, as shown in Table 3 . The concrete steps are as follows:

(1) determine the original Matrix according to Table 2:

$$
E_{i}=-\ln (n)^{-1} \sum_{j=1}^{n} f_{i j} \ln f_{i j}
$$

Among them, 


$$
f_{i j}=c_{i j} / \sum_{i=1}^{m} c_{i j},(i=1,2, \ldots m ; j=1,2, \ldots n)
$$

From this, the information entropy of each index is $E_{1}, E_{2}, \ldots, E_{i}$. Calculate the degree of variance for indicator " $i$ ". Finally, the weights of various kinds of boundary risks are calculated:

$$
\begin{aligned}
& d_{i}=1-E_{i} \\
& W_{i}=\frac{d_{i}}{\sum_{i=1}^{m} d_{i}}
\end{aligned}
$$

Table 3. Weight value of all kinds of boundary risk factors

\begin{tabular}{c|c|c}
\hline $\begin{array}{c}\text { Number of } \\
\text { evaluation } \\
\text { indicators }\end{array}$ & $E_{i}$ & $W_{i}$ \\
\hline $\mathrm{a}_{11}$ & 0.839 & 0.043 \\
\hline $\mathrm{a}_{12}$ & 0.793 & 0.055 \\
\hline $\mathrm{a}_{21}$ & 0.843 & 0.042 \\
\hline $\mathrm{a}_{22}$ & 0.623 & 0.100 \\
\hline $\mathrm{a}_{31}$ & 0.754 & 0.065 \\
\hline $\mathrm{a}_{32}$ & 0.795 & 0.054 \\
\hline $\mathrm{a}_{33}$ & 0.394 & 0.161 \\
\hline $\mathrm{a}_{41}$ & 0.682 & 0.084 \\
\hline $\mathrm{a}_{42}$ & 0.646 & 0.094 \\
\hline $\mathrm{a}_{51}$ & 0.813 & 0.050 \\
\hline $\mathrm{a}_{52}$ & 0.793 & 0.055 \\
\hline $\mathrm{a}_{61}$ & 0.821 & 0.047 \\
\hline $\mathrm{a}_{62}$ & 0.430 & 0.150 \\
\hline
\end{tabular}

In the same way, calculate the weight of the market, economy, and other variables on the system as follows:

$$
\begin{aligned}
& \left(a_{1}, a_{2}, a_{3}, a_{4}, a_{5}, a_{6}\right) \\
& =(0.117,0.122,0.241,0.141,0.123,0.255)
\end{aligned}
$$

\subsection{Regional Real Estate Investment Risk System Dynamics}

According to the established system flow chart and the weight of each boundary risk factor, the risk System dynamics equation and related functions can be established:

(1) Level variable:

market risk $=0.055 \times a_{12}+0.065 \times 0.043 \times a_{11}$

Policy risk $=0.042 \times a_{21}+0.100 \times a_{22}$

Information risk $=0.050 \times a_{51}+0.055 \times a_{52}+$ $0.141 \times\left(0.084 \times a_{41}+0.094 \times a_{42}\right)$
Economic risk $=0.065 \times a_{31}+0.054 \times a_{32}+0.161 \times$ $a_{33}+0.123 \times\left(0.050 \times a_{51}+0.055 \times a_{52}\right)+0.122 \times$ $\left(0.042 \times a_{21}+0.100 \times a_{22}\right)$

Technical risk $=0.047 \times 0.084 \times a_{41}+0.094 \times a_{42}$

Environmental risk $=0.047 \times a_{61}+0.150 \times a_{62}$

(2) Table function: Financing difficulties, Rising interest rates, Inflation, Change in demand structure, Regulatory Policy, A broken law, Technical applicability, Number of public emergencies, Number of meteorological, Flood and drought disasters.

(3) Auxiliary variable: Real Estate Investment risk $=0.007 \times$ market risk $+0.122 \times$ Policy risk $+0.241 \times$ Economic risk $+0.141 \times$ Technical risk $+0.123 \times$ Information risk $+0.255 \times$ Environmental risk

\section{Simulation analysis of System dynamics model}

\subsection{Model hypothesis}

Based on the research method of System dynamics, this paper takes the risk level of real estate investment as the output, and the economy, market and policy as the input, and identifies the influence of each variable on the system risk level. To ensure the scientific and rigorous nature of the study, the following assumptions are made:

Assumption 1: The risk level of the system is determined by the factors mentioned above. Assuming that the main variables are consistent with the causality diagram above, in order to find the most sensitive risk factors, only one factor is adjusted at a time.

Assumption 2:To ensure the applicability of the model, it is assumed that there are no other risk factors affecting the real estate investment system during the simulation period.

Assumption 3:The initial value of each risk factor is 0 . The simulation time is 10 years, the simulation step length DT is 1 year.

\subsection{Sensitivity analysis of the System dynamics model}

According to the design of the above parameters and the actual situation of the last two years, the sensitivity of the real estate investment risk system in Tianjin was debugged, the public emergency and the interest rate rise and so on to the Tianjin Real Estate Investment Risk Influence is remarkable, see figure 3 and figure 4. 


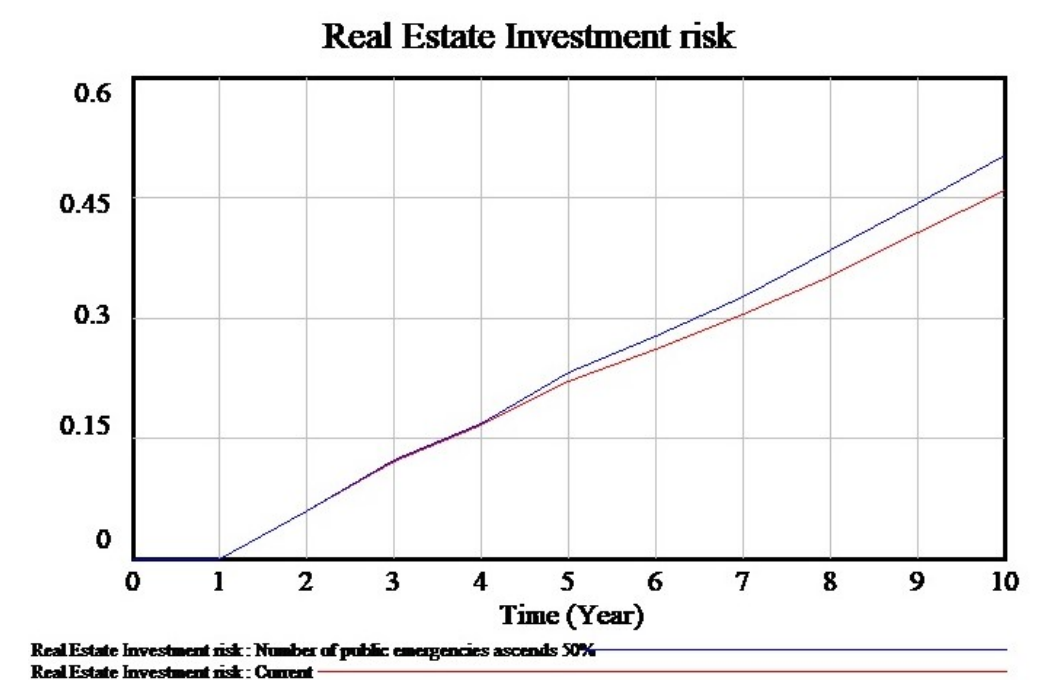

Figure 3. The impact of public emergency on investment risk in real estate market

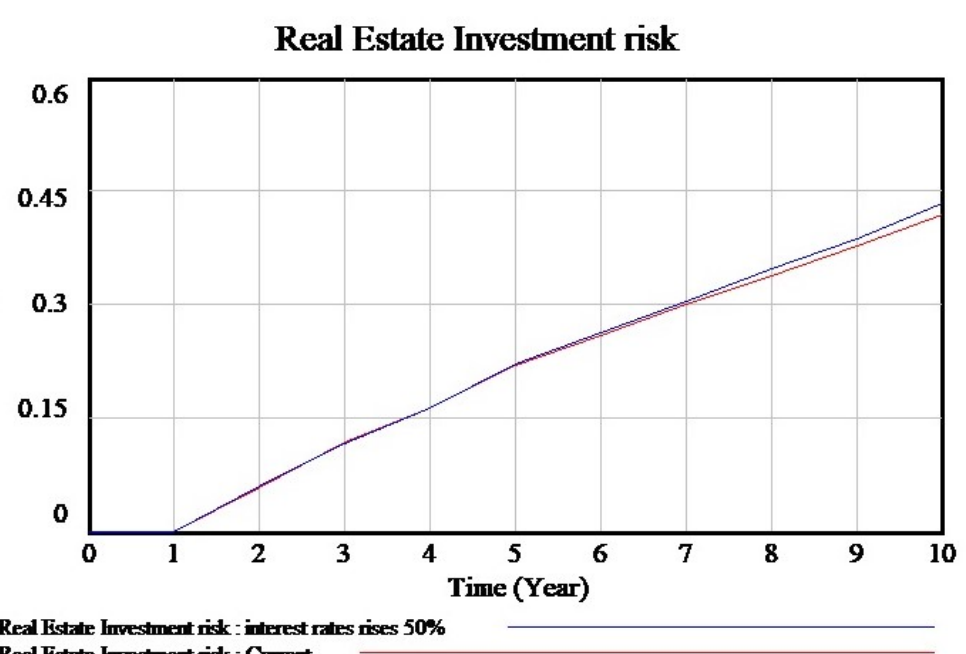

Real Fistate Investment risk : inlerest
Real Fistate Investment risk : Coment

Figure 4. The influence of rising interest rate on investment risk in real estate market

Public Emergency.The outbreak of new pneumonia in 2020 had a great impact on the real estate market of Tianjin. Suppose in the original state, the risk Coefficient of public emergency is 0 . When it rises suddenly, the change of investment risk of Tianjin real estate market is shown in figure 3 . It can be seen that due to the impact of the new pneumonia, the real estate market investment risk showed a sharp rise in the trend. Therefore, in order to reduce the negative impact of this on real estate enterprises, on the one hand, the government can take the policy of reducing or exempting enterprises from taxes and fees to reduce enterprises costs; on the other hand, the relevant departments should also take active measures, preventing the further spread of adverse effects.

Interest rates go up.As can be seen from figure 4, the loan interest rate has a negative feedback effect on the real estate investment, namely: The higher the interest rate, the less the investment amount, the greater the investment risk. The influence of interest rate on real estate investment is mainly concentrated in the prophase of investment. In recent years, the government has introduced a number of related policies, raising loan interest rates to control overdevelopment of real estate projects, but considering the long-term development of the real estate market in the future, it can not rise indefinitely, otherwise, it will bring great risks to the real estate enterprises, attack the enthusiasm of enterprises and hinder the orderly development of the market economy. Therefore, referring to the relevant literature, it is suggested that government departments should speed up the reform of interest rate marketization and establish a reasonable interest rate reform mechanism. By regulating the real estate market and financial market, the interest rate policy can play a regulatory role in the real estate market.

\section{Conclusion}

The development of the real estate market will be affected by the change of the external environment. This paper analyzes the main factors that affect the risk of real estate investment from the perspective of the external environment. Using the method of System dynamics, this paper constructs a System dynamics model of real estate investment risk in Tianjin. After combing the literature, the paper uses Vensim software to model and simulate the relevant data. The results show that:(1) among the six 
influencing factors, because the adjustment of technology, market and policy will affect the economy, so the economic risk has the biggest influence (2) the rising of interest rate in economic risk and the unexpected public events in environmental risk have great influence on the investment risk of Tianjin real estate market.

\section{Acknowledgments}

The author wishes to express her most sincere gratitude to the reviewers and editors. And this work was supported by the [Special Fund for Natural Science, Renai College, Tianjin University] under Grant [number XX19009].

\section{References}

1. Zhao L. (2018) Risk Identification and prevention in the whole process of real estate investment project under the background of new normal. Science and education guide, 30: 157-158.

2. Deng XY, Seow EO, Qian MJ. (2018) Real Estate Risk, Corporate Investment and Financing Choice. The Journal of Real Estate Finance and Economics, 57:87-113.

3. Liu W, Xia EJ, Yang SH. (2016) Research on risk evaluation of real estate trust Investment Fund. Shandong Social Sciences, 8:154-159.

4. Huang MF, Yao MX, Lu BT. (2017) Application of Bayesian network decision in risk control of real estate investment. Statistics and decision making, 21:71-74.

5. Zhou QQ, Han YN. (2018) Research on investment risk evaluation and control of real estate project based on mould and hierarchy comprehensive evaluation method. Financial Theory and practice, 6:104-110.

6. Zhang P, Ma L, Zhai BW. (2018) Research on Grey model and evaluation of real estate investment risk. Research on technical economy and management, 4:22-25.

7. Zhong YG, Jia XJ, Qian Y. (2013) System dynamics. Science Press, Beijing.

8. Yu JF, Wang K. (2019) Simulation analysis of human behavior and safety System dynamics during subway tunnel construction. Science and Technology for development, 15:703-708.

9. Gao J, Wu XT. (2020) Risk evolution evaluation engineering project based system dynamics model. Statistics and decision making, 4:185-188.

10. Xu CG, Zhou JK. (2019) System Dynamics modeling and analysis of PPP project performance. Monthly Journal of Accounting,8:173-176.

11. Fang Y, Ma XX. (2020) Real Estate Project Construction Safety Risk Assessment based on entropy weight-grey correlation method. Journal of Chengdu Institute of Technology, 23:68-72.

12. Liao M. (2016) Reliability and validity of questionnaire and application of SPSS software. Technology Outlook, 16:290. 